\title{
Damage Behaviour and Stress Concentration Factor of Open Hole Tensile (OHT) Glass Fibre Reinforced Polymer (GFRP) Composites
}

\author{
J. Bale* \\ Department of Mechanical Engineering, Universitas Nusa Cendana, 85001 Kupang, \\ NTT, Indonesia \\ *Email: jefri_bale@staf.undana.ac.id \\ Phone: +628113830900; Fax: +62380881557
}

\begin{abstract}
In many applications of composites, open-hole frequently includes for various purposes. However, further study on open-hole behaviour is still required, including on its strength and damage properties by combining experimental testing, real-time observations and calculations based on theoretical analysis and simulation model. The objective of this study is to understand the effect of an open-hole glass fibre reinforced polymer (GFRP) composites on tensile (static) properties, damage behaviour through Non-destructive Testing (NDT) Thermography and stress concentration factor (SCF). This study used an open-hole rectangular of GFRP specimens that fabricated by filament winding (FW) method and resin transfer moulding (RTM) method. It is found that the RTM specimens generate $\approx 170 \%$ higher of tensile strength and $\approx 100 \%$ higher of tensile modulus compared to the FW specimens. Infra-red (IR) camera shown the good detection on damage behaviour based on temperature increase at elastic and failure phase. Moreover, theoretical analysis and simulation results shown the good correlation where SCF reaches more than 4 times at the edge of the hole. This study concludes that open-hole on GFRP composites affects the tensile properties and generates damage marked by temperature increase and high SCF at the edge of the hole.
\end{abstract}

Keywords: Open-hole GFRP; tensile; thermography; damage; stress concentration factor

\section{INTRODUCTION}

Nowadays, composites reinforced by fibre have been widely used in various applications in industries, where the main advantages of fibre composites is an excellent of strength to weight ratio and specific strength/stiffness properties. An open-hole structure of composite has been used to assembly component such as joint structure. In its application, this structure carries loads and produce failure, and it is important to determine the behaviour of failure from design and life-time point of view [1,2]. Under static loads, the presence of an open-hole creates stress concentrations which can cause initial damage in crack form and has an effect on stress or strain gradients or reduction in strength $[3,4,5]$. A study about an open-hole condition of composites materials should be a serious concern because it will be one of the main factors that determine the success in composites application as part of a complex structure.

There are four basic damage mechanisms in fibre reinforced polymer composite under tensile loading in general $[6,7]$. The first damage that initiated by the weakest fibre fail; the second damage produced by matrix cracking that caused by the higher stress 
concentration in the matrix due to fibre fail; the third damage dominated by interfacial debonding of fibre/matrix. The final damage occurred in the form of fibre pullout and fibre breakage. These damage mechanisms have a significant effect on material state and the structural design in several applications, it is thus creating the need for non-destructive testing (NDT) to have a better understanding about the damage behaviour of composite by monitoring its evolution and accumulation [8]. Furthermore, NDT is used to maintain the composites structure in terms of its quality and reliability [9].

Thermography is a non-destructive testing method for observing the temperature evolution on specimen surface in real-time condition experimentally. The thermography allows detecting object radiation in the infrared range of the electromagnetic spectrum to obtain information concerning images of radiation and the amount of radiation emitted and transforms into the temperature $[10,11]$. The temperature then represented in the form of thermographic images and measured from the intensity of the infrared radiations using Stefan-Boltzmann's law, which is described below.

$$
\frac{q}{A}=\sigma \varepsilon T^{4}
$$

where $q$ is the rate of energy emission (W), $A$ is the area of the emitting surface $\left(\mathrm{m}^{2}\right), \sigma$ is the Stefan-Boltzmann's constant $\left(=5.676 \times 10^{-8} \mathrm{Wm}^{-2} \mathrm{~K}^{-4}\right)$ and $\varepsilon$ is the emissivity of the surface. For a perfect blackbody, $\varepsilon=1$ and for real surface, $\varepsilon<1$.

Thermography has been shown to be an effective technique for detecting the temperature variation due to applied stress in composites material. It is well known that when a material is subjected to a loading, heat transfer occurs both in elastic and plastic regime under adiabatic conditions. Stanley and Chan [12] presented the relationship between temperature changes and applied stress on the surface of composite material with plane stress conditions, as follows:

$$
\Delta T=-\frac{T}{\rho C_{p}}\left(\alpha_{1} \Delta \sigma_{1}+\alpha_{2} \Delta \sigma_{2}\right)
$$

where, $\alpha_{1}$ and $\alpha_{2}$ are the coefficients of thermal expansion $\left(\mu \mathrm{m} / \mathrm{m}^{\circ} \mathrm{C}\right), C_{p}$ is the specific heat at constant pressure $\left(\mathrm{J} / \mathrm{g}{ }^{\circ} \mathrm{C}\right), \rho$ is density $(\mathrm{g} / \mathrm{cc})$ and $\Delta \sigma$ is the change in stress $\left(\mathrm{N} / \mathrm{m}^{2}\right)$ where subscripts 1 and 2 denote the longitudinal and transverse to fibre directions.

Furthermore, most research works based on thermography on composite material has shown that thermal analyses can indicate the damage location on the specimen surface and successfully detected the damage formation and propagation based on the temperature evolution under static loading conditions [13, 14, 15, 16, 17, 18, 19].

Based on the mentioned literature, combining the experimental testing, damage observation by NDT thermography and calculation of stress concentration factor (SCF) of open-hole GFRP composites could be introduced as novel information of this article. Thus, the objective of the present work is to investigate the effect of open-hole glass fibre reinforced polymer (GFRP) composites on tensile properties and stress concentration where damage assessment will be carried out with the NDT thermography under static tensile loading. In the work of this paper, the experimental test is running under static loading and GFRP test specimens are produced by filament winding (FW) method and resin transfer moulding (RTM) method. The importance of the study is generating information about strength and damage properties of open-hole GFRP composites that can be applied as components to facilitate the joining of structural elements. 


\section{EXPERIMENTAL SETUP}

The mechanical test was conducted under a tensile static test machine as illustrated in Figure 1. In this test, the tested specimen is a rectangular shape with an open-hole of unidirectional GFRP composites with two types of fabrication process; filament winding (FW) method and resin transfer moulding (RTM) method with epoxy as the matrix. The experimental tests were run according to ASTM D5766 at a constant strain rate of 0.1 $\mathrm{mm} / \mathrm{min}$. During the tensile test, an infra-red (IR) camera was placed in front of the specimen to follow the temperature change on the specimen surface to focus on damage area at the edge of the hole, as seen in Figure 2.

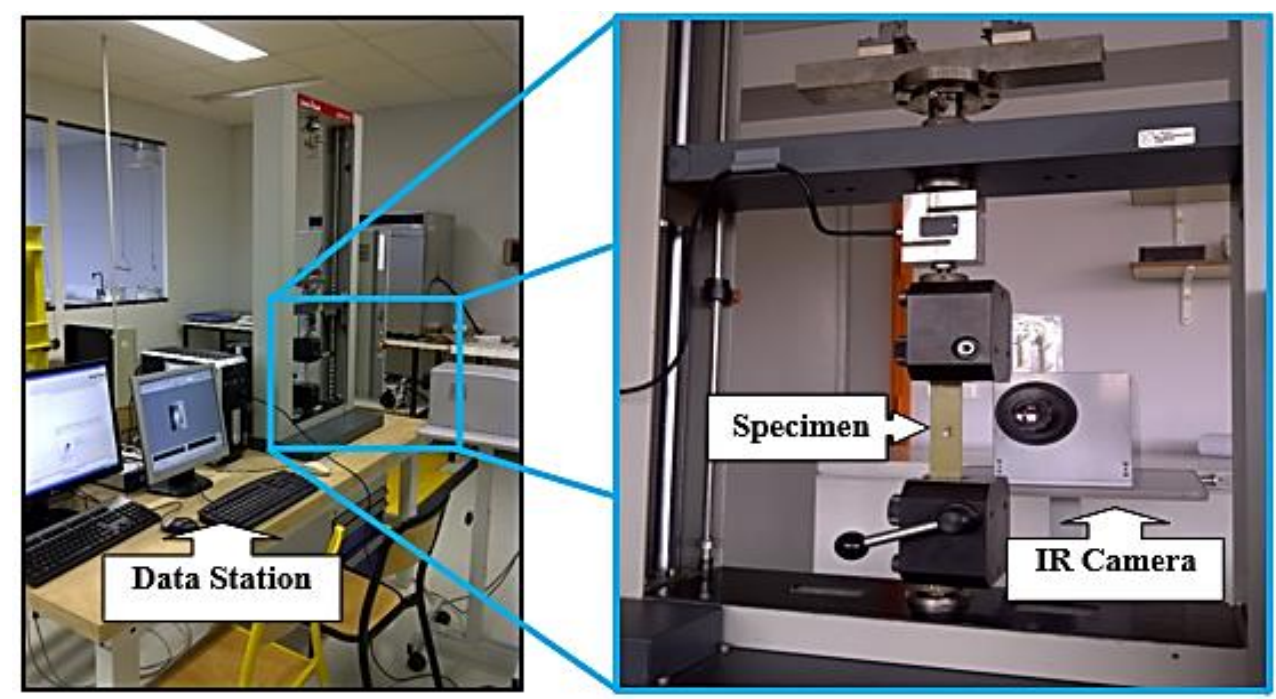

Figure 1. Experimental setup.

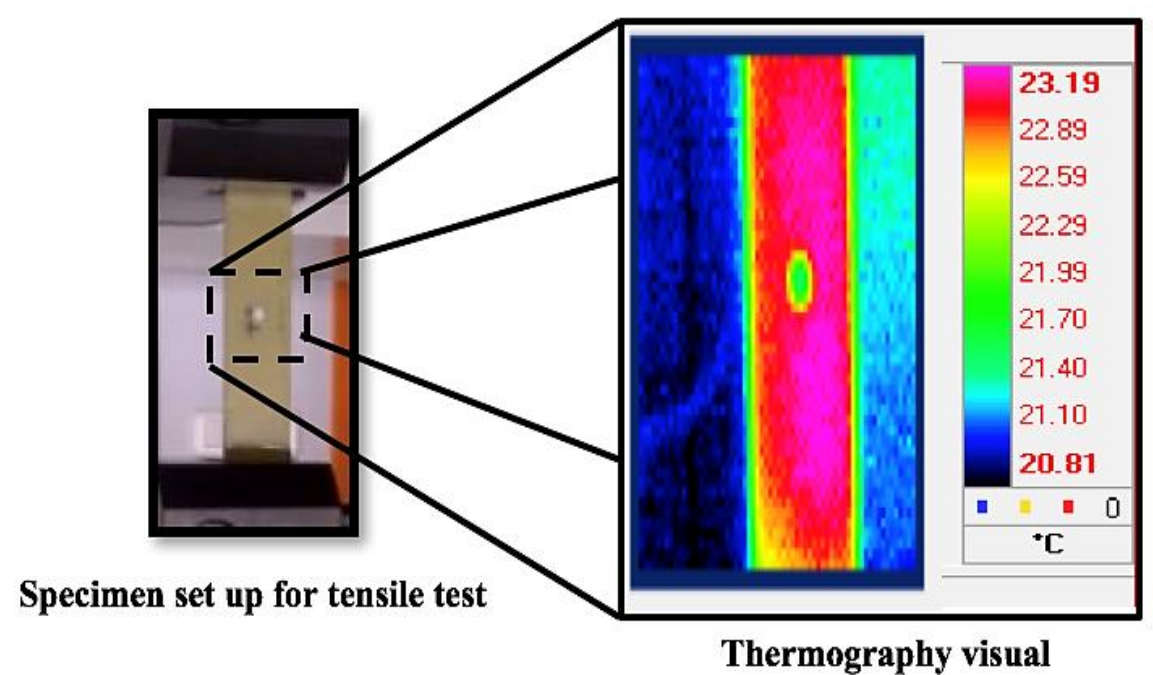

Figure 2. Observation area of IR camera. 


\section{RESULTS AND DISCUSSION}

The proposed results in Figure 3 indicate the typical tensile load versus displacement curves obtained from the GFRP composites under static loading. From Figure 3, it is shown that the fabrication process has an influence on the force and displacement behaviour of the GFRP composites where RTM method produces higher force and displacement compared to FW method. Different static properties of tensile strength (UTS), strain to failure and tensile modulus are obtained based on the results of load versus displacement curves, as seen in Figure 4.

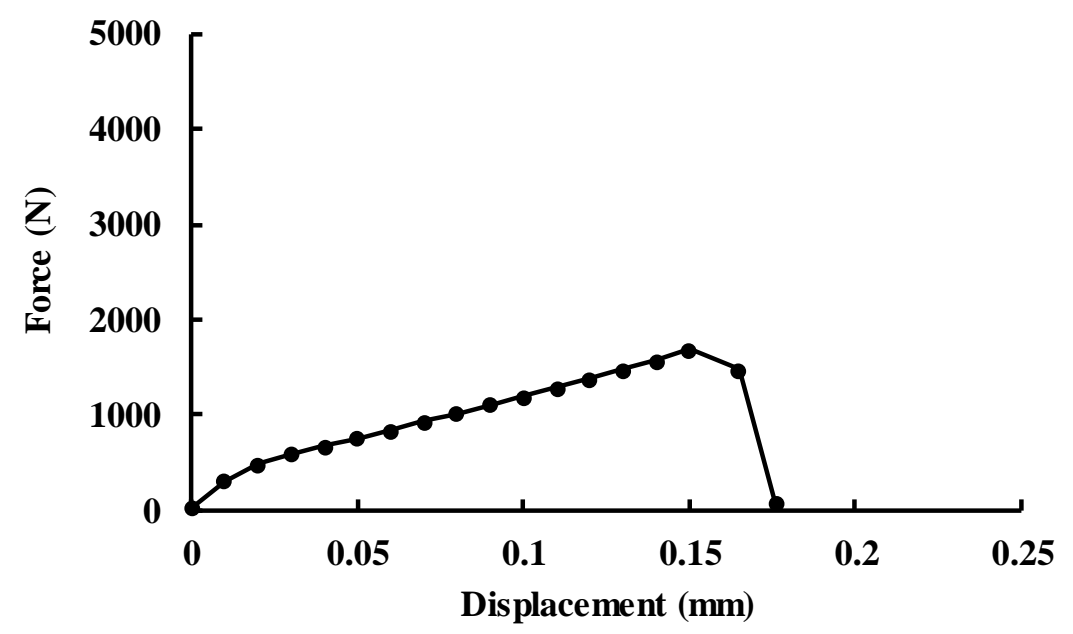

(a) FW specimen

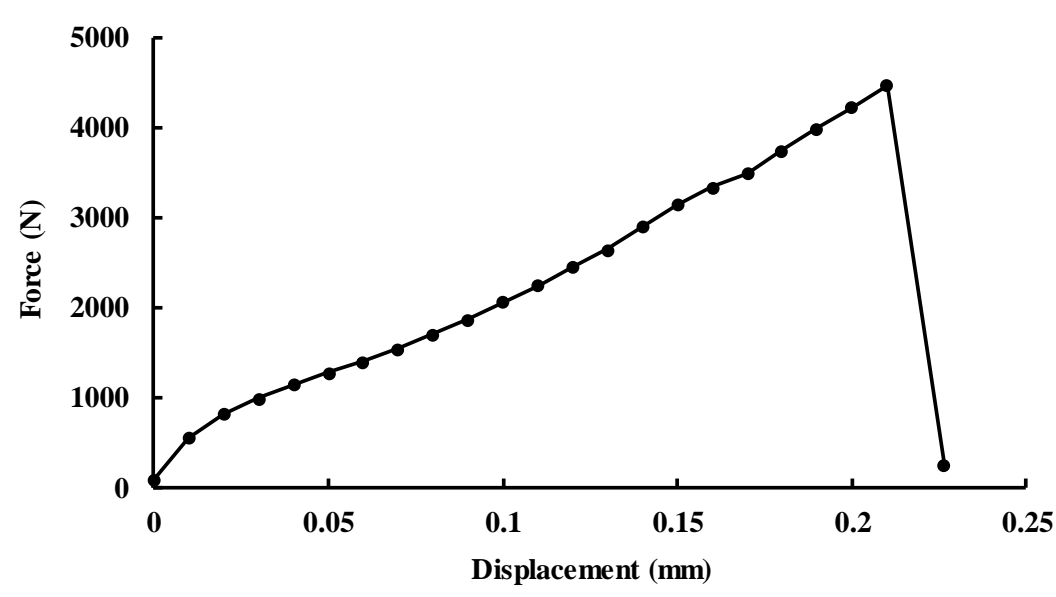

(b) RTM specimen

Figure 3. Load versus displacement.

As observed from Figure 4, It can be found that RTM process has a profound impact on the tensile properties of composites. The RTM specimen exhibit a higher tensile strength $(\approx 57 \mathrm{MPa})$ and around $1.15 \%$ for the strain to failure (see Figure 4(a)). The RTM specimen also present the highest static properties of tensile modulus about 46 $\mathrm{GPa}$ and reaches two times compared to FW specimen. 


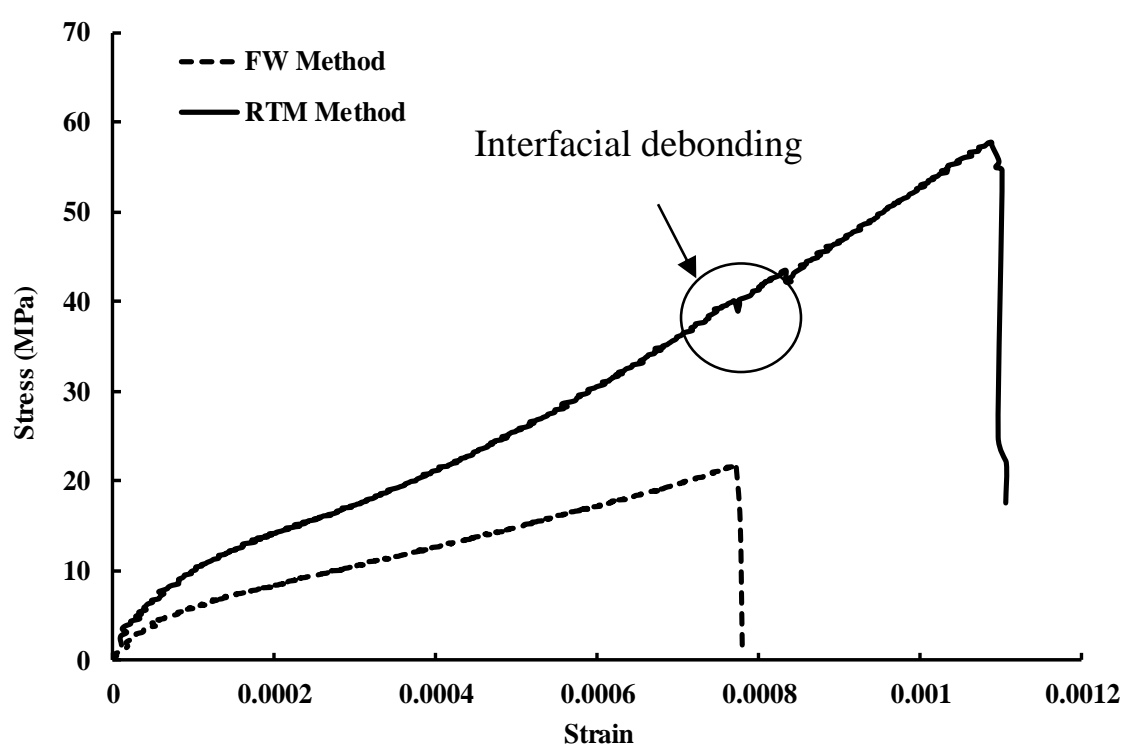

(a) Stress versus strain

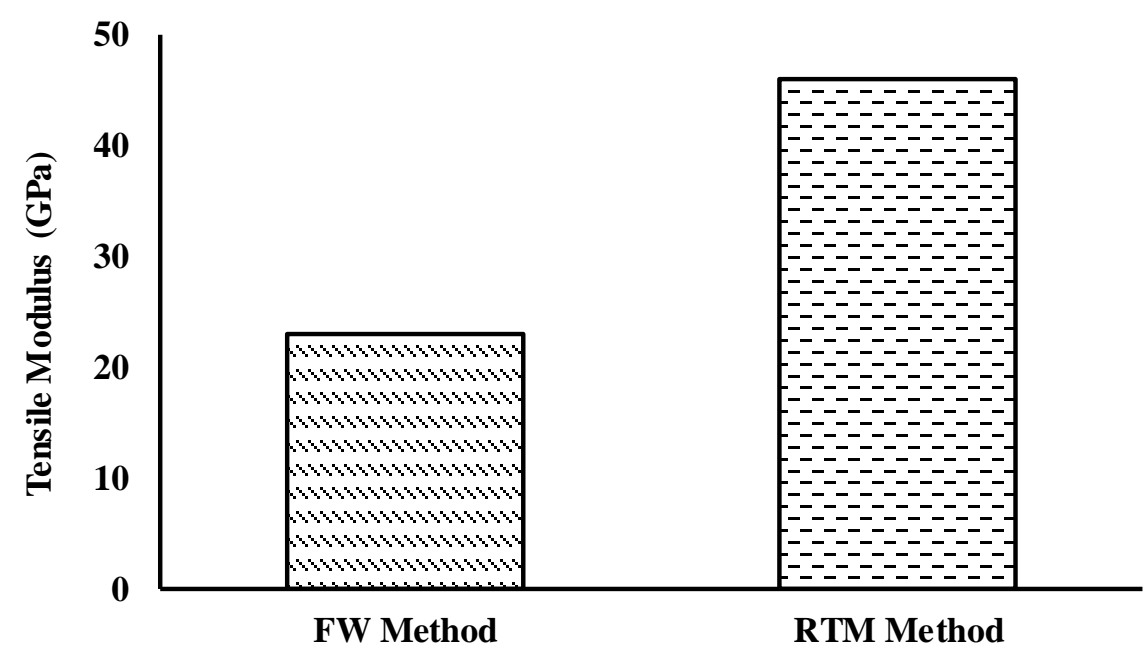

(b) Tensile modulus

Figure 4. Stress versus strain of GFRP composites.

The probable reason is the RTM process improve the function of the matrix to holding the fibres together and transferring the applied load to the fibres. The efficiency of fibre function as reinforcement in composite depends on the interface of fibre-matrix and the capability to transfer load/stress from the matrix to the fibre [20, 21, 22, 23, 24]. Furthermore, RTM specimen also contained fibre in parallel orientation with the loading direction which could be the reason to produce higher tensile properties compared to FW specimen. Figure 5 shows the thermography images on GFRP composites specimen that indicates the temperature value on the specimen surface.

From Figure 5 it can be noted that the IR camera detects a distribution of temperature based on the discoloration of surface specimen. The thermography images describes well the damage at the hole area and can be useful for damage monitoring. The temperature changes with the load increase were due to the stress concentration that initiates the presence of damage mechanisms [14, 25, 26, 27]. The temperature distribution for both specimens consist of two phases, as illustrate in Figure 6. 


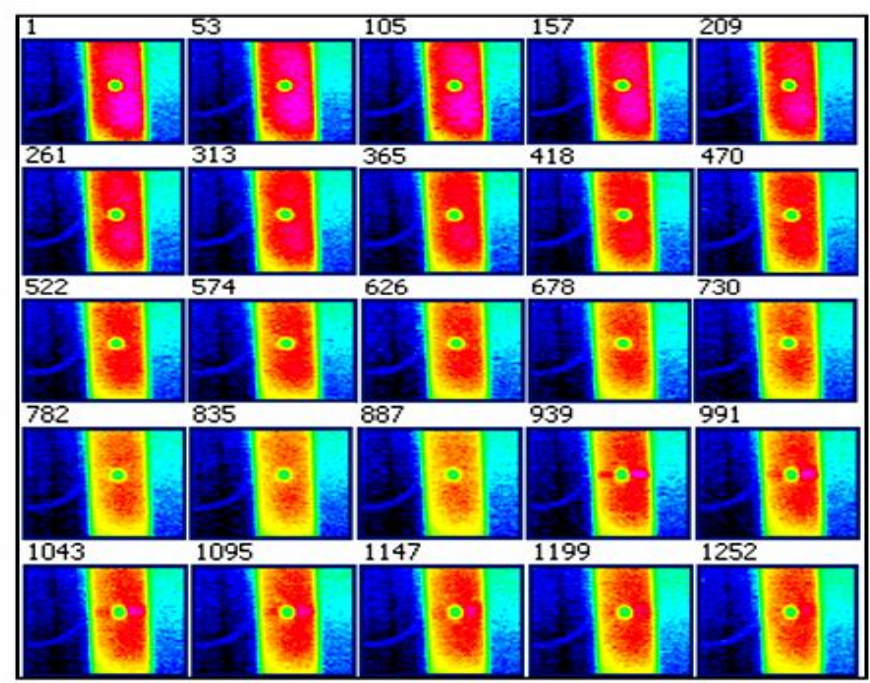

(a) FW specimen

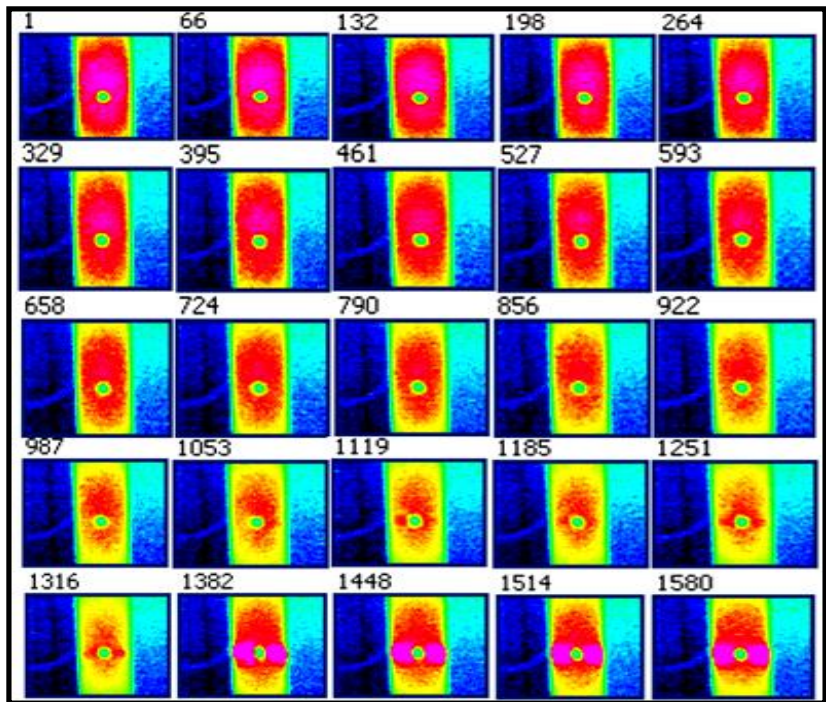

(b) RTM specimen

Figure 5. Thermography images of GFRP composites.

Each phase of temperature distribution has different behaviour [17, 28, 29, 30]. The first phase of the elastic phase generates a decreasing trend of temperature behaviour due to the absorption energy by the specimen from the given load. This process produces the elastic increase in volume which lead to initiate the presence of first microdamage mechanism of matric cracking. The second phase of failure phase shows an increase trend of temperature behaviour suddenly caused by the energy released from the specimen due to the presence of final failure in the form of a macro matrix and fibre breakage.

Based on temperature distribution of FW specimen at the edge of the hole area (in Figure 6(a)), it shows the temperature decrease, $\Delta \mathrm{T}$ of $\approx 0.6-0.7^{\circ} \mathrm{C}$ at the elastic phase. At the failure phase, the temperature suddenly increases and reaches $\Delta \mathrm{T}$ of $\approx 1.2-1.4$ ${ }^{\circ} \mathrm{C}$ when the final failure appears. The temperature profile (in 3D) when the final failure happens can be seen in Figure 7. 


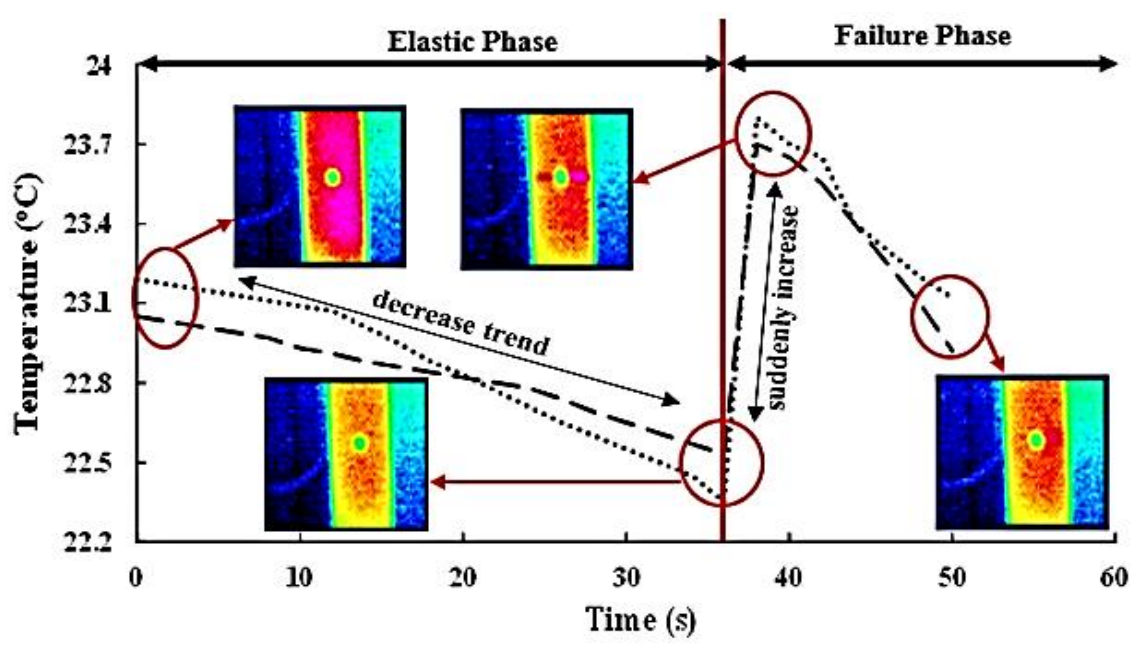

(a) FW specimen

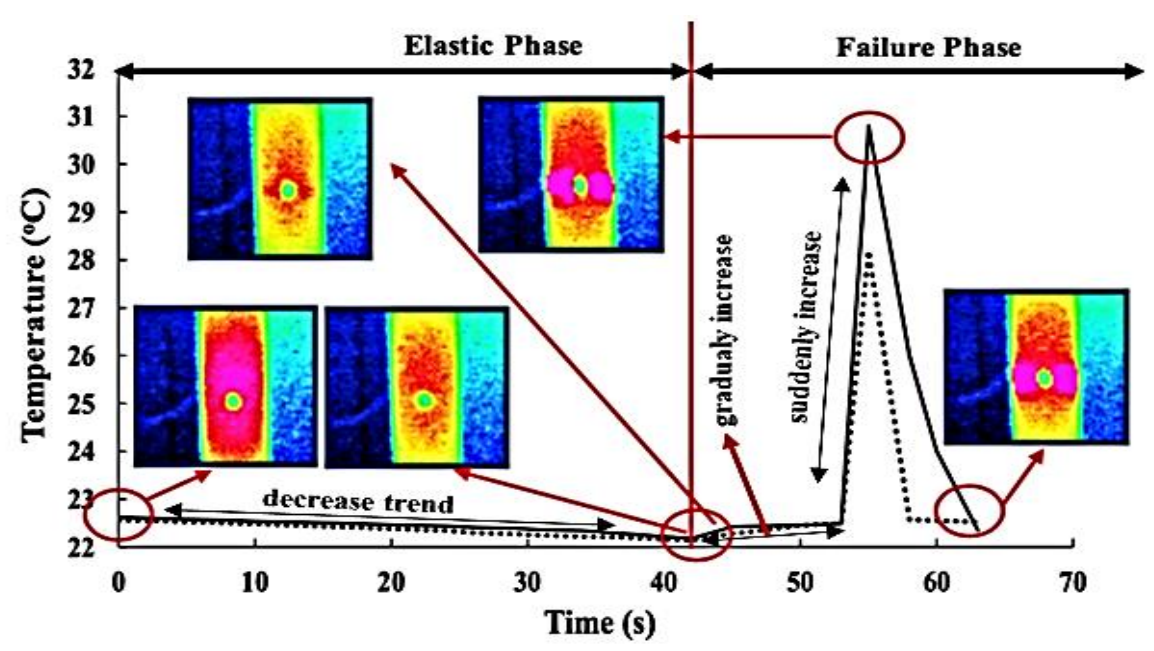

(b) RTM specimen

Figure 6. Temperature distribution of GFRP composites.

For RTM specimen, the temperature at the edge of hole area shows the decreasing trend ( $\Delta \mathrm{T}$ ) of $\approx 0.5-0.6^{\circ} \mathrm{C}$ as the process of absorption energy by the specimen. At the failure phase, there are two types of temperature increases shown in Figure 6(b). The first type indicated by a small suddenly increase of temperature, $\Delta \mathrm{T} \approx 0.3^{\circ} \mathrm{C}$ that possibly due to the presence of micro matrix cracking. The temperature gradually increase that caused by damage propagation in the form of interfacial debonding and the matrix still able to transfer the given load to the fibre. Interfacial debonding occurs at some points of stressstress relationship (see Figure 4(a)) but the specimen shows that each matrix and fibre still functioning to receive the increase in stress and strain. Thereafter, at the end of failure phase, the second type of high suddenly increase of temperature reaches the highest point at $\Delta \mathrm{T} \approx 5-8^{\circ} \mathrm{C}$ due to the interfacial debonding enlarges gradually and extended to the end of specimen width until final failure occurs in a form of matrix and fibre breakage. Similar behaviour was also discussed by previous study on the behaviour of interfacial bonding between CFRP sheets and steel plates [31]. The temperature profile (in 3D) when the final failure appears can be seen in Figure 8. 


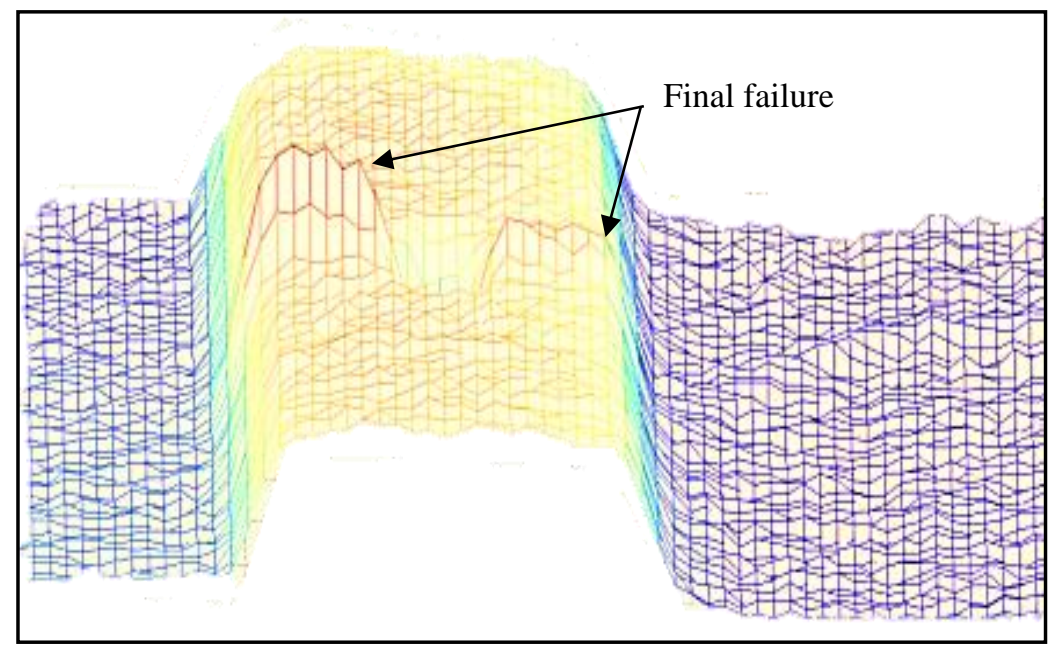

Figure 7. Temperature profile of final failure of FW specimen

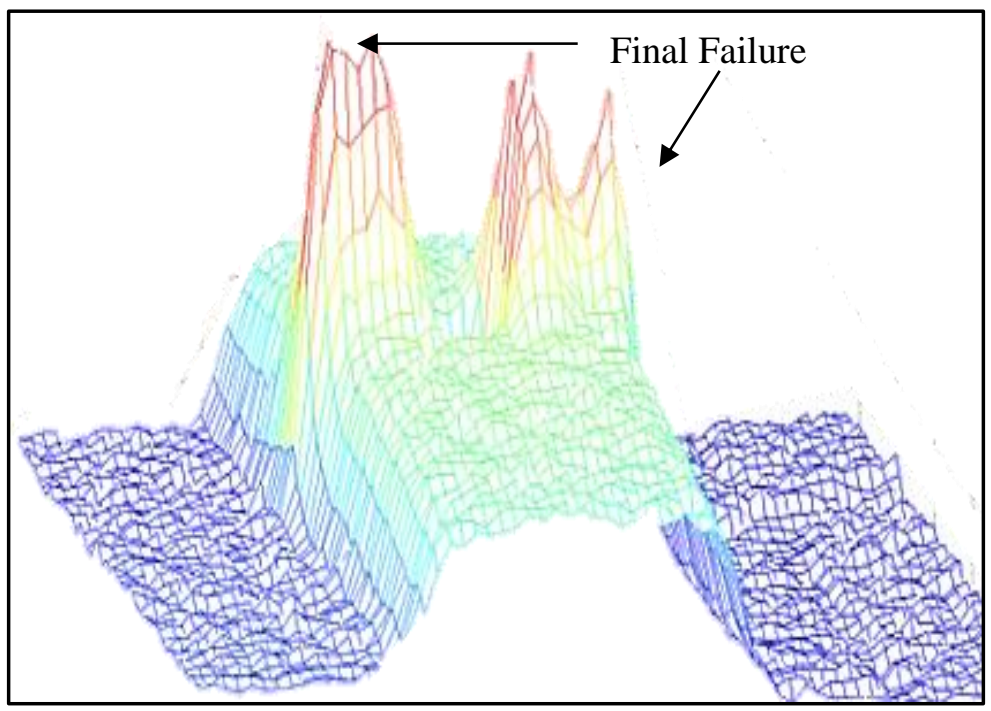

Figure 8. Temperature profile of final failure of RTM specimen.

From tensile test and thermography image, it was found that the damage occurs at the edge of the hole and perpendicular against the loading direction, as seen in Figure 9. The damage mechanism for each specimen shows a different mechanism after the first damage. The FW specimen shows the brittle damage behaviour and perpendicular to the loading direction. In general, the damage starts with micro matrix cracking mechanism, then fibre breaking occurs and initiates extensive matrix cracking and later the damage rapidly increases which cause the final failure of the specimen. Figure 10 shows the damage observation of FW specimen. 


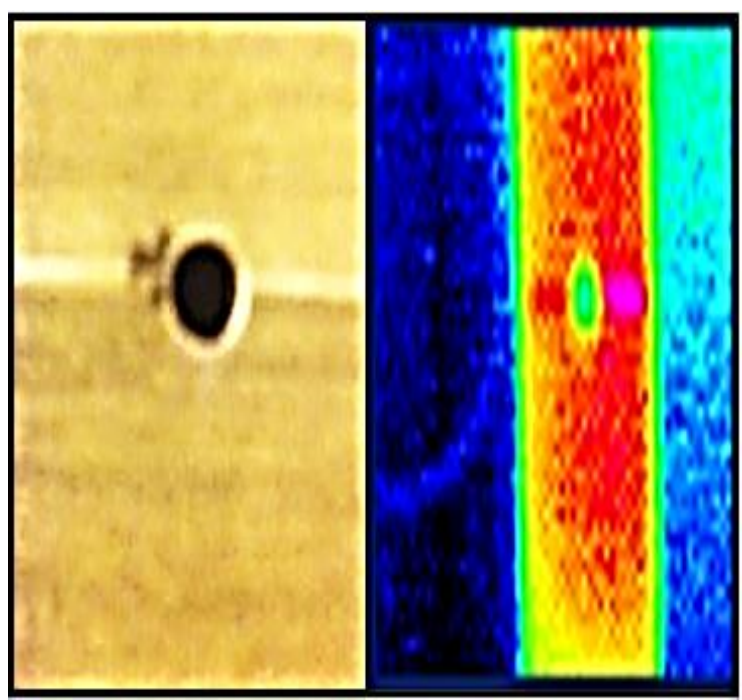

(a) FW specimen

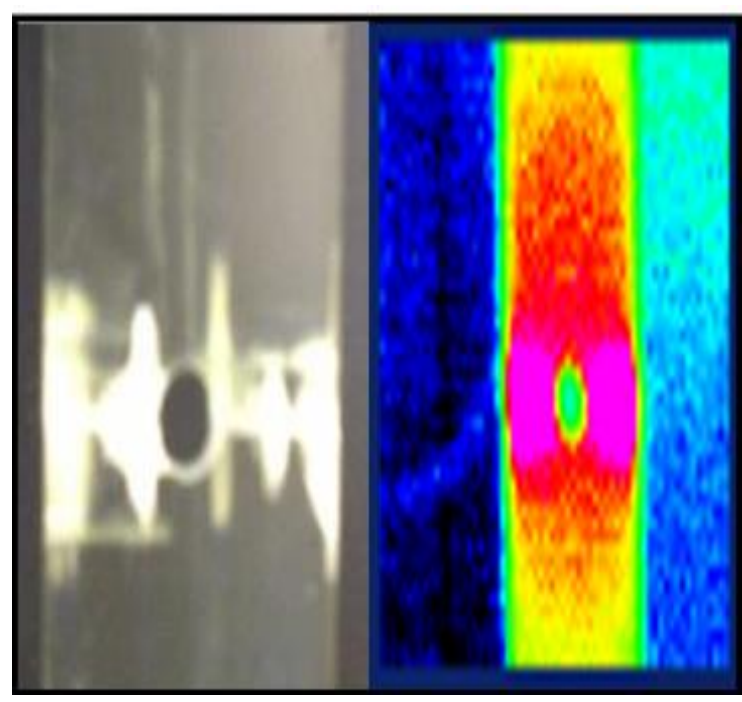

(b) RTM specimen

Figure 9. Final failure of GFRP composites.

The failure of the RTM specimen in tension is fairly straight and perpendicular to the loading axis. The initial damage occurs in the form of cracking emanating from the edge of the hole due to matrix cracking and interfacial fibre/matrix debonding [32]. It has been observed that after initial damage, the specimen still sustains the load under increasing displacement. In this damage area, longitudinal matrix and fibre splitting also occur at the edge of the hole due to the fail of fibre in longitudinal orientation (see Figure 11). The final failure of specimens seems to occur when the damage area reaches a certain distance to the end of the width side of the specimen.

From the damage observation for both type of the specimens, it can be noted that: the damage mechanisms show a brittle behaviour of GFRP composites material which initiate by matrix cracking; the damage behaviour indicates that the fibre orientations have a significant influence on the location of damage area; the hole increases stress concentration that induces strength reduction and initiates damage. 
This condition also confirms by the calculation of stress concentration factor (SCF) which shows the highest stress concentration occurs in a perpendicular direction with the loading direction at the edge of the hole, as explained by previous studies [33, 34]. The effect of an open hole on the SCF was calculated and the specimen illustration in a tensile test in the axis-1 direction is shown by Figure 12.

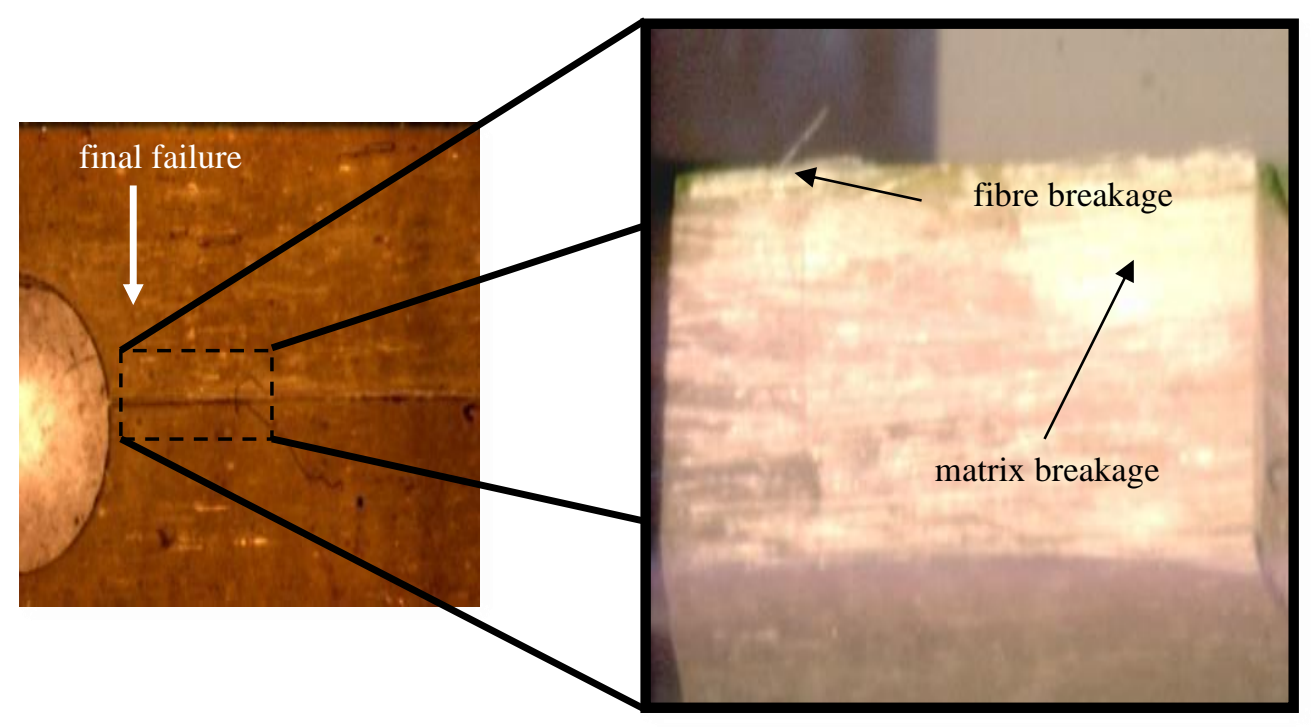

Figure 10. Damage appearance of FW specimen.
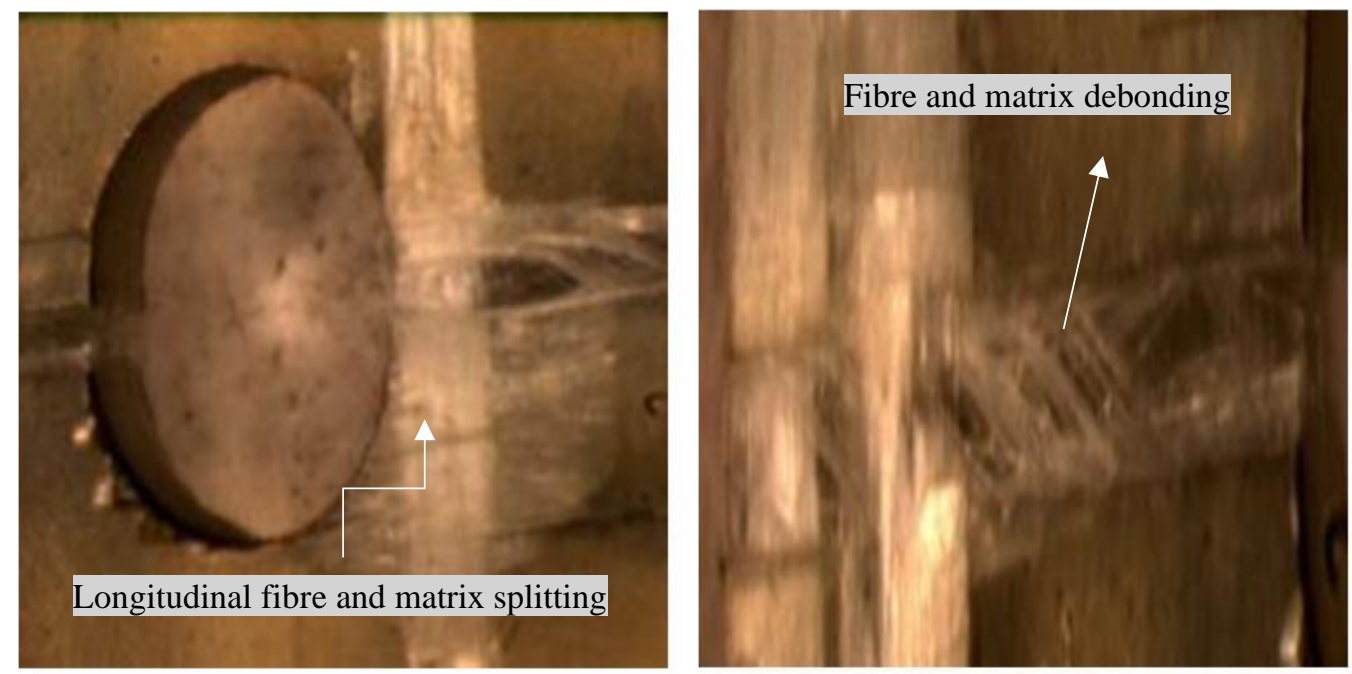

Figure 11. Damage appearance of RTM specimen.

From the specimen specification (i.e. FW specimen), the ply engineering elastic constants with respect to the principal elastic axes $\{\mathrm{L}, \mathrm{T}\}$ are given by [35]:

i. $\quad E_{x}=E_{L}=$ Modulus of elasticity of single ply in fibre direction

ii. $\mathrm{E}_{\mathrm{y}}=\mathrm{E}_{\mathrm{T}}=$ Modulus of elasticity of single ply transverse to fibre direction

iii. $\mathrm{G}_{\mathrm{xy}}=\mathrm{G}_{\mathrm{LT}}=$ shear modulus of single ply associated with $\{\mathrm{L}, \mathrm{T}\}$ system

iv. $\quad v_{\mathrm{xy}}=v_{\mathrm{LT}}=$ poisson's ratio of single ply with respect to $\{\mathrm{L}, \mathrm{T}\}$ system 


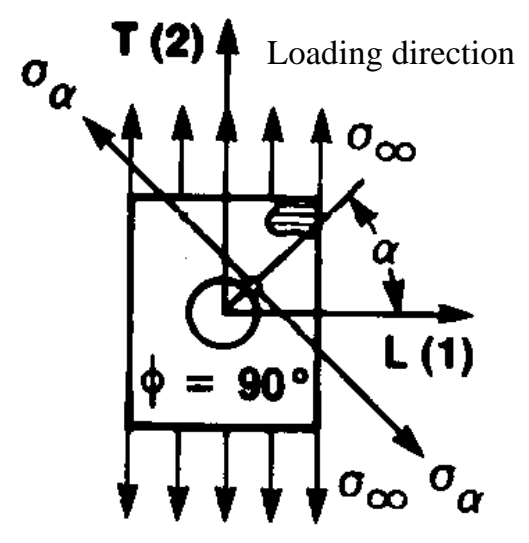

Figure 12. Loading and principal axes.

Using the specification of FW specimen, the ply constants with respect to axes $\{1,2\}$ can be calculated from the following equations:

$$
\begin{aligned}
& E_{1}=E_{L} /\left[\cos ^{4} \theta+\frac{E_{L}}{E_{T}} \sin ^{4} \theta+\frac{1}{4}\left(\frac{E_{L}}{G_{L T}}-2 v_{L T}\right) \sin ^{2} 2 \theta\right] \\
& E_{2}=E_{L} /\left[\sin ^{4} \theta+\frac{E_{L}}{E_{T}} \cos ^{4} \theta+\frac{1}{4}\left(\frac{E_{L}}{G_{L T}}-2 v_{L T}\right) \sin ^{2} 2 \theta\right] \\
& G_{12}=E_{L} /\left[1+2 v_{L T}+\frac{E_{L}}{E_{T}}-\left(1+2 v_{L T}+\frac{E_{L}}{E_{T}}-\frac{E_{L}}{G_{L T}}\right) \cos ^{2} 2 \theta\right]
\end{aligned}
$$

The stress concentration factor, $K$ for the specimen was calculated from:

$$
K=\frac{\sigma_{\alpha}}{\sigma_{\infty}}=\frac{E_{\alpha}}{E_{1}}\left\{\begin{array}{c}
{\left[-\cos ^{2} \emptyset+(k+n) \sin ^{2} \varnothing\right] k \cos ^{2} \alpha+\left[(1+n) \cos ^{2} \varnothing-k \sin ^{2} \varnothing\right]} \\
\sin ^{2} \alpha-n(1+k+n) \sin \varnothing \cos \varnothing \sin \alpha \cos \alpha
\end{array}\right\}
$$

where:

$$
\begin{aligned}
& \frac{E_{\alpha}}{E_{1}}=1 /\left[\sin ^{4} \alpha+\frac{E_{1}}{E_{2}} \cos ^{4} \alpha+\frac{1}{4}\left(\frac{E_{1}}{G_{12}}-2 v_{12}\right) \sin ^{2} 2 \alpha\right] \\
& k=\sqrt{\frac{E_{1}}{E_{2}}} \\
& n=\sqrt{2\left(\frac{E_{1}}{E_{2}}-v_{12}\right)+\frac{E_{1}}{G_{12}}}
\end{aligned}
$$

From the calculation, it shows that the SCF could reach $\mathrm{K}=4.635$. It means that at $\alpha=0$, the stress produces the highest concentration and reaches more than four times compared to the given stress, as found for carbon fibre reinforced polymer/CFRP [4]. As a result, this location is the damage location that caused by the highest SCF. This result 
has a good correlation with the tensile test and thermography visual (see Figure 9) that the failure occurs in perpendicular with the loading direction or parallel with the fibre orientation. $\mathrm{K}$ value shows that when the loading direction is transverse to the fibre direction, the value of $K$ reaches 0.469 at two points $\left( \pm 90^{\circ}\right)$ or in other words, it experiences almost zero stress due to the tensile loading. The (-) sign shows that in that point, hole experience a compressive stress. Table 1 summarizes the SCF, K for each value of $\alpha=0^{\circ}-90^{\circ}$ with fibre orientation in a perpendicular direction with loading axis $\left(\theta=90^{\circ}\right)$.

Table 1. Stress concentration factor.

\begin{tabular}{lc}
\hline Location of $\sigma_{\alpha}(\alpha)$ & Stress Concentration Factor $(\mathrm{K})$ \\
\hline 0 & 4.635 \\
$\pm 10^{\circ}$ & 3.504 \\
$\pm 20^{\circ}$ & 1.933 \\
$\pm 30^{\circ}$ & 0.912 \\
$\pm 45^{\circ}$ & 0.274 \\
$\pm 60^{\circ}$ & $\approx 0$ \\
$\pm 70^{\circ}$ & -0.285 \\
$\pm 80^{\circ}$ & -0.415 \\
$\pm 90^{\circ}$ & -0.469 \\
\hline
\end{tabular}

A simulation also conducts to analyse the stress distribution at the edge of the hole for the FW specimen specification. Figure 13 below shows the simulation model.

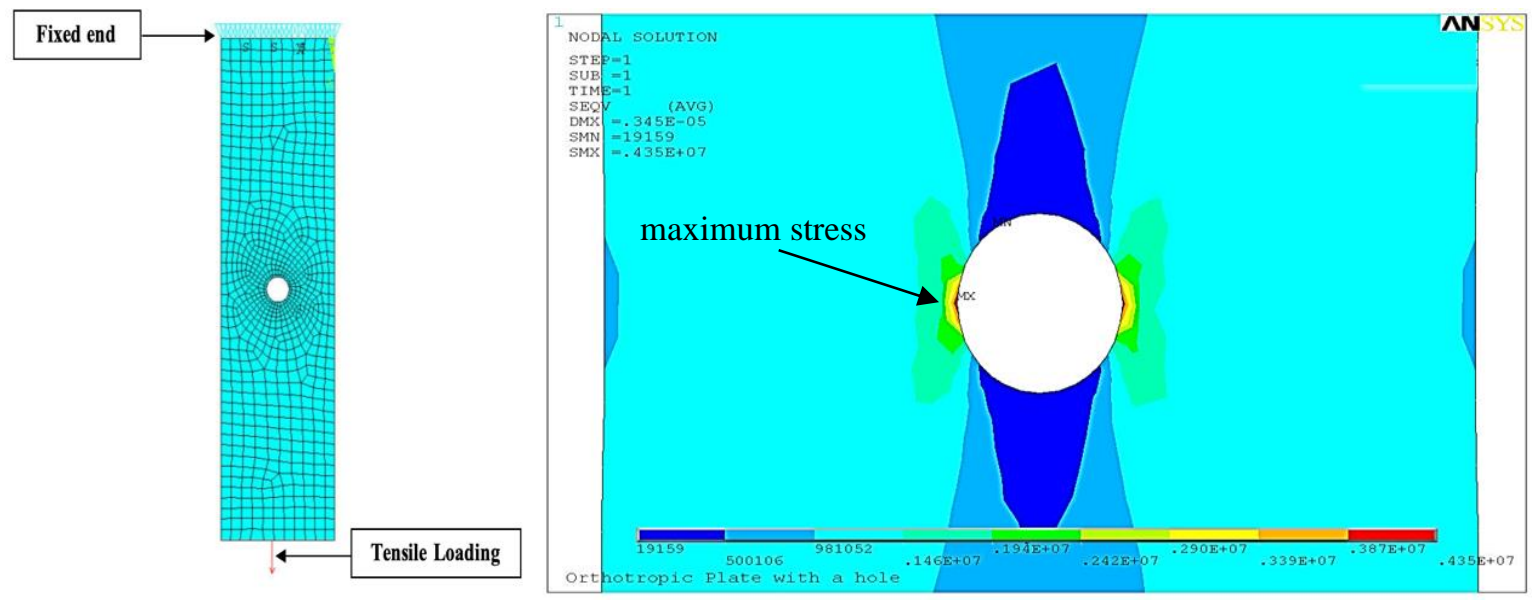

Figure 13. Simulation of GFRP composites.

From Figure 13, it indicates that the maximum stress $(\mathrm{mx})$ occurs at the perpendicular area against the loading direction at the edge of the hole where reaches more than four times (SMX value). The results show a good correlation with the analytical results (see Table 1) according to the value of SCF, as seen in Figure 14. It is clear that the presence of the hole and the fibre orientation $(\theta)$ have a significant influence on the SCF in GFRP composites [36, 37, 38]. 


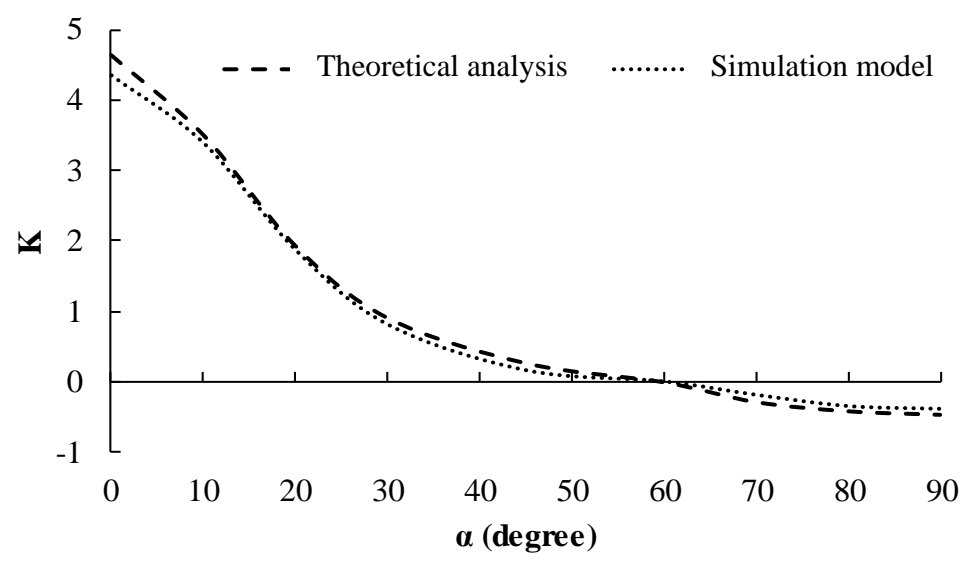

Figure 14. Analytical and simulation on stress concentration factor of GFRP composites.

\section{CONCLUSION}

This work discussed the tensile properties damage behaviour by NDT thermography and stress concentration factor of open-hole GFRP composites under static loading. Based on the tensile tests, the tensile properties of GFRP composites show brittle behaviour and depends on the type of fabrication process where RTM method produces $\approx 170 \%$ higher of tensile strength and $\approx 100 \%$ higher of tensile modulus compared to FW method. Based on the observation result of NDT thermography, it shows that temperature distribution successfully identifies the damage behaviour where consists of elastic phase marked by temperature decrease and failure phase shown by a slow and sudden rise of temperature. In terms of stress concentration factor, an open-hole generates more than four times of maximum stress at the edge of the hole $(\alpha=0)$ of GFRP composites based on analytical and simulation results. Thus, this study concludes that open-hole affects the tensile properties of GFRP composites and the initial damage that signed by temperature increase and high stress concentration factor. Further studies are suggested on the effect of hole(s) formations and fibre orientations on the tensile properties under static and fatigue test conditions and using several NDT methods as observation technique on damage behaviour of GFRP composites.

\section{ACKNOWLEDGEMENT}

The author thanks LEME laboratory of University Paris Nanterre and PSA Peugeot Citroën in France for providing facilities.

\section{REFERENCES}

[1] Zahari R, Kamarulazizi S, Abdul Majid DLA. Tensile behaviour of unbalanced woven c-glass/epoxy composite laminated plate with and without circular cutouts. Jurnal Mekanikal 2012; 34: 57-65.

[2] Kumar A, Agrawall A, Ghadai R, Kalita K. Analysis of stress concentration in orthotropic laminates. Procedia Technology 2016; 23: 156-162.

[3] Zakaria KA, Jimit RH, Ramli SNR, Aziz AA, Bapokutty O, Ali MB. Study on fatigue life and fracture behaviour of fibreglass reinforced composites. Journal of Mechanical Engineering and Sciences 2016; 10(3): 2300-2310. 
[4] Makki MM, Chokri B. Experimental, analytical, and finite element study of stress concentration factors for composite materials. Journal of Composite Materials 2016; 0(0): 1-12.

[5] Khechai A, Tati A, Guerira B, Guettala A, Mohite PM. Strength degradation and stress analysis of composite plates with circular, square and rectangular notches using digital image correlation. Composite Structures 2018; 185: 699-715.

[6] Mishnaevsky Jr L, Brøndsted P. Micromechanical modeling of damage and fracture of unidirectional fibre reinforced composites: A review. Computational Materials Science 2009; 44: 1351-1359.

[7] Brunner AJ. Fibre-reinforced polymer composites test specimen design for selected damage mechanisms. Journal of Materials: Design and Applications 2018; 0(0): 1-10.

[8] Diamanti K, Soutis C. Structural health monitoring techniques for aircraft composite structures. Progress in Aerospace Sciences 2010; 46: 342-352.

[9] Bibi I, Murat S, Fromme P. Propagation and scattering of guided waves in composite plates with defects. International Journal of Automotive and Mechanical Engineering 2016; 13(3): 3728 - 3741.

[10] Rojek M, Wrobel G. Thermographic method of fatigue assessment of polymeric materials. Journal of Achievements in Material and Manufacturing Engineering 2010: 88-93.

[11] Haneef T, Lahiri BB, Bagavathiappan S, Mukhopadhyay CK, Philip J, Chandra Rao BP, Jayakumar T. Study of the tensile behaviour of AISI type 316 stainless steel using acoustic emission and infrared thermography techniques. Journal of Material Research and Technology 2015; 4(3): 241-253.

[12] Stanley P, Chan WK. The application of thermoelastic stress analysis techniques to composite material. Proceeding of Springer Conference on Experimental Mechanics 1987; 536-544.

[13] Usamentiaga R, Venegas P, Guerediaga J, Vega L, Molleda J, Bulnes FG. Infrared thermography for temperature measurement and non-destructive testing. Sensors 2014; 14: 12305-12348.

[14] Harizi W, Chaki S, Bourse G, Ourak M. Mechanical damage assessment of glass fibre-reinforced polymer composites using passive infrared thermography. Composites: Part B 2014; 59: 74-79.

[15] Libonati F, Vergani L. Damage assessment of composite materials by means of thermographic analyses. Composites: part B 2013; 50: 82-90.

[16] Emery TR, Dulieu-Barton JM. Thermoelastic stress analysis of damage mechanisms in composite materials. Composites: Part A 2010; 41: 1729-1742.

[17] Kutin M, Ristic S, Puharic M, Vilotijevic M, Krmar M. Thermographic testing of epoxy-glass composite tensile properties. Contemporary Materials II 2011: 88-93.

[18] Bale J, Valot E, Polit O, Bathias C, Monin M, Soemardi T. Thermal phenomenon of glass fibre composite under tensile static and fatigue loading. Journal of Mechanical Engineering and Sciences 2017; 11(2): 2755-2769.

[19] Bale J, Valot E, Monin M, Laloue P, Polit O, Bathias C, Soemardi T. Damage observation of glass fibre/epoxy composites using thermography and supported by acoustic emission. Applied Mechanics and Materials 2014: 187-190.

[20] Athipathi K, Hegde Sowmitha Vijay V. Evaluation of mechanical behaviour of natural fibre hybrid composite material. International Journal of Advanced Research in Science, Engineering and Technology 2016; 3(5): 2041-2049.

[21] Jiang X, Gao Q. Stress-transfer analysis for fibre/matrix interfaces in short-fibre- 
reinforced composites. Composites Science and Technology 2001; 61: 13591366.

[22] Dilandro L, Dibenedetto T, Groeger J. The effect of fibre-matrix stress transfer on the strength of fibre-reinforced composite materials. Polymer Composites 1988; 9(3): 209-221.

[23] Azwa ZN, Yousif BF, Manalo AC, Karunasena W. A review on the degradability of polymeric composites based on natural fibres. Materials and Design 2013; 47: 424-442.

[24] Hadzreel MAM, Aisha ISR. Effect of reinforcement alignment on the properties of polymer matrix composite. Journal of Mechanical Engineering and Sciences 2013; 4: 548-554.

[25] Chrysafi AP, Athanasopoulos N, Siakavellas NJ. Damage detection on composite materials with active thermography and digital image processing. International Journal of Thermal Sciences 2017; 116: 242-253.

[26] Broughton WR, Gower MRL, Lodeiro MJ, Pilkington GD, Shaw RM. An experimental assessment of open-hole tension-tension fatigue behavior of a GFRP laminate. Composites: Part A 2011; 42: 1310-1320.

[27] Goidescu C, Welemane H, Garnier C, Fazzini M, Brault R, Péronnet E, Mistou S. Damage investigation in CFRP composites using full-field measurement techniques: Combination of digital image stereo-correlation, infrared thermography and X-ray tomography. Composites: Part B 2013; 48: 95-105.

[28] Vergani L, Colombo C, Libonati F. A review of thermographic techniques for damage investigation in composites. Frattura ed Integrità Strutturale 2014; 27: 112.

[29] Libonati F. Damage analysis of composites by means of thermography. In: 9th Youth Symposium on Experimental Solid Mechanics, Trieste, Italy, pp. 25-28; 2010.

[30] Colombo C, Libonati F, Vergani, L. Study of the mechanical characteristics of GFRP by thermography. In: 16th International Conference on Composite Structures, Porto, Portugal, 2011.

[31] Zhang L, Cao S, Tao X. Experimental study on interfacial bond behaviour between CFRP sheets and steel sheets under fatigue loading. Materials 2019; 12(377): 1-14.

[32] Bale J. The damage observation of composite using non destructive testing (NDT) method. Ph.D Thesis, Universite Paris Nanterre, Nanterre, France, 2014.

[33] Mollenhauer D, Iarve E, Kim R. Experimental/analytical examination of damage in a composite containing a hole. Retrieved from http://www.emimac.org; 21 February, 2019.

[34] Toubal L, Karama M, Lorrain B. Stress concentration in a circular hole in composite plate. Composite Structures 2005; 68: 31-36.

[35] Marshall IH. Composite structures 5. 1st ed. New York: Elsevier Science Publishing Co, Inc; 1989.

[36] Jain NK, Banerjee M, Sanyal S. Three dimensional analysis for effect of fibre orientation on stress concentration factor in fibrous composite plates with central circular hole subjected to in-plane static loading. In: 7th International Conference on Intelligent Systems and Control, Coimbatore, India, pp. 502-505; 2013.

[37] Nithish Prabhu T, Prithviraj H, Dhanush C, Pratheek P, Jagannatha Guptha VL. Experimental investigation of stress concentration factor in a unidirectional carbon/e-glass fibre hybrid composite. International Journal of Metallurgical \& 
Materials Science and Engineering 2014; 4(2): 17-24.

[38] Mittal ND, Jain NK. Effect of fibre orientation on stress concentration factor in a laminate with central circular hole under transverse static loading. Indian Journal of Engineering \& Material Sciences 2008; 15: 452-458. 